\title{
Extensive gliosis in the wall of cervico-dorsal syrinx masquerading intramedullary tumor
}

\author{
Amit Agrawal, Rajesh Dulani ${ }^{1}$, Arvind Bhake ${ }^{2}$, Kishore M . H iwale ${ }^{2}$, Anita M ahadevan ${ }^{3}$, S. K. Shankar ${ }^{3}$ \\ Departments of Surgery, ${ }^{1}$ Orthopedics and ${ }^{2}$ Pathology, Datta Meghe Institute of Medical Sciences, Sawangi (Meghe), Wardha, \\ ${ }^{3}$ Department of Neuropathology, National Institute of Mental Health and Neurosciences, Bangalore, India
}

A 32-year-old gentleman presented with weakness, tingling, and numbness of all the four limbs for one month. He was operated for hydatid liver four years back. There was grade $4 / 5$ weakness of all the four limbs with spasticity in the lower limbs and decreased sensation below C4. Reflexes were exaggerated in lower limbs and sluggish in upper limbs. Magnetic resonance imaging (MRI) showed extensive cervico-dorsal syrinx [Figures 1-3]. Gadolinium-enhanced images showed heterogeneously enhancing cystic lesion at C4-5 [Figures 4 and 5]. At surgery a gray-yellow, firm, welldefined mass was resected. The patient deteriorated by two grades immediate postoperatively, but recovered thereafter. Histopathological examination showed cystic lesion lined by ependymal lining. The wall showed dense fibrillary isomorphic gliosis entrapping anterior horn cells with numerous Rosenthal fibres [Figure 6]. No immature neuronal or glial elements were found. Characteristic biphasic pattern of a pilocytic astrocytoma with loose microcystic zones

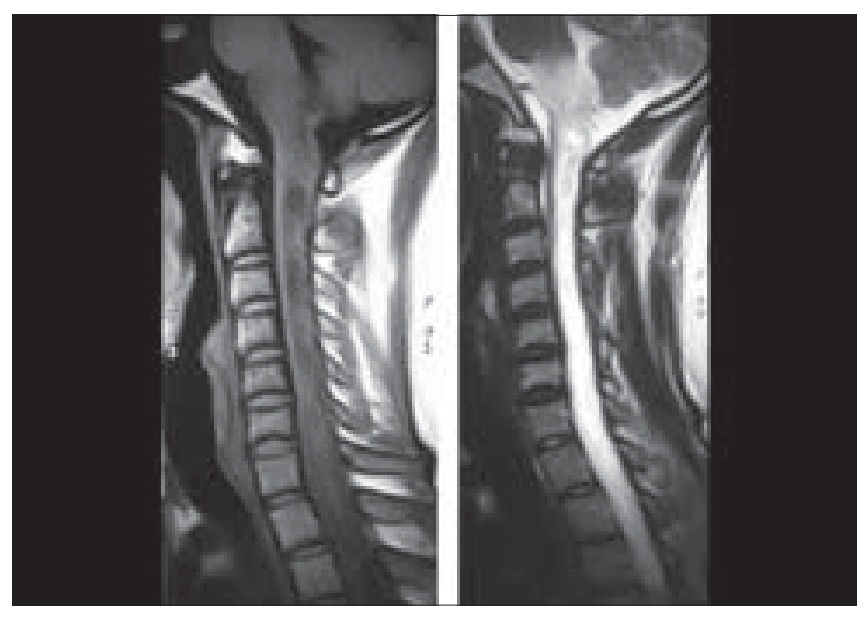

Figure 1: MRI T1 and T2 sagittal image showing extensive syring all along the cervical and dorsal region associated with cord widening and areas of isointensity to hypointensity and eosinophillic granular bodies was not evident. The findings were suggestive of extensive gliosis in the wall of the syrinx [Figure 6].

In idiopathic syringomyelia, there are longitudinally oriented cavities with surrounding gliosis, attributed to arachnoiditis without any evidence of a true neoplasm. ${ }^{[1,2]} \mathrm{As}$ in the present case clinically and radiologically these lesions can masquerade as intramedullary tumor with syringomyelia. ${ }^{[1,2]}$ The leading edge of the syrinx cavity dissects along longitudinal tissue planes leading to hypertrophic and hyperplastic gliotic changes. ${ }^{[1,3]}$ Gliosis is proportional not only to the age of the lesion but to the severity of the forces acting upon the walls, ${ }^{[4]}$ and can be seen as circumferential bands producing "beaded" appearance. ${ }^{[3,5]}$ Gliosis is commonly associated with syringomyelia ${ }^{[1,2,5]}$ and on MRI can show heterogeneous contrast enhancement. ${ }^{[2]}$

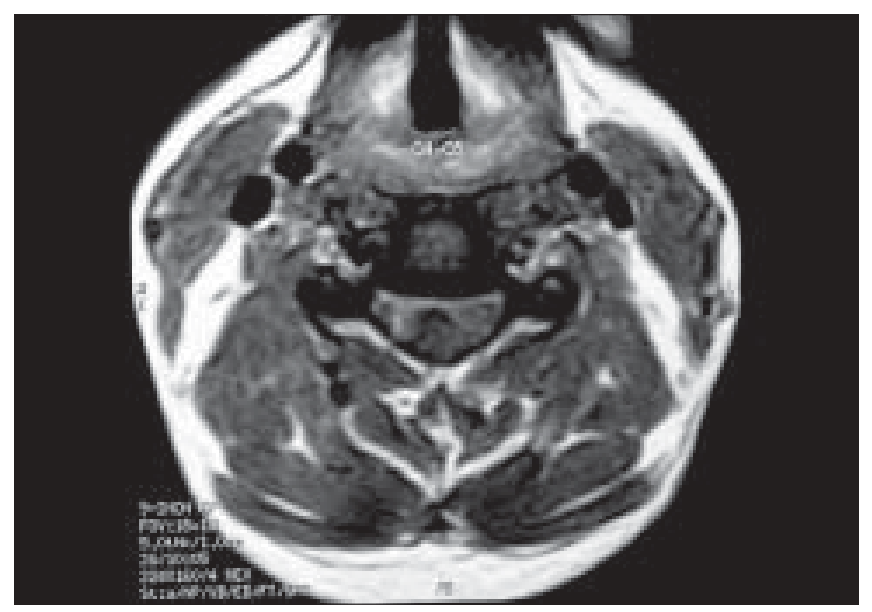

Figure 2: MRI T1 axial image showing hypointensity causing the widening of cord 


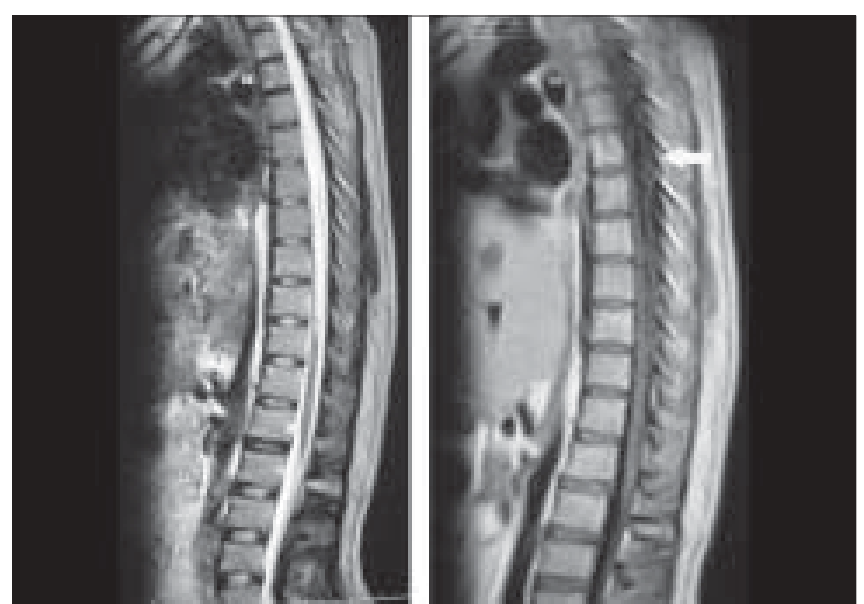

Figure 3: MRI T1 and T2 sagittal image showing extensive syring involving the dorsal cord

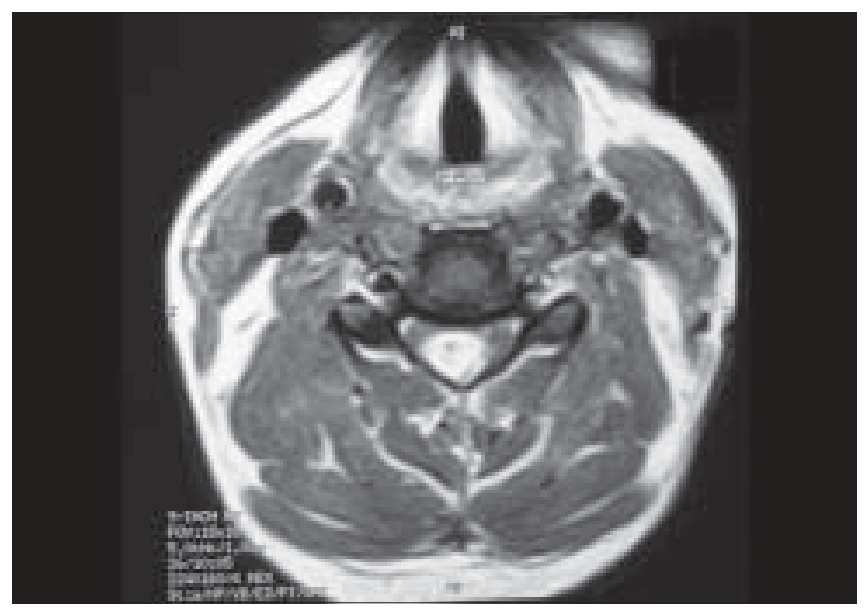

Figure 5: MRI axial T1-weighted image of the cervical cord showing heterogeneous enhancement of the intramedullary mass

Address for correspondence: Dr. Amit Agrawal,

Clinical and Administrative Head, Division of Neurosurgery, Datta M eghe Institute of Medical Sciences, Sawangi (Meghe), Wardha - 442004 , Maharashtra, India. Email: dramitagrawal@gmail.com

DOI: $10.4103 / 0028-3886.51312$

\section{References}

1. Sherman JL, Barkovich AJ, Citrin CM. The MR appearance of
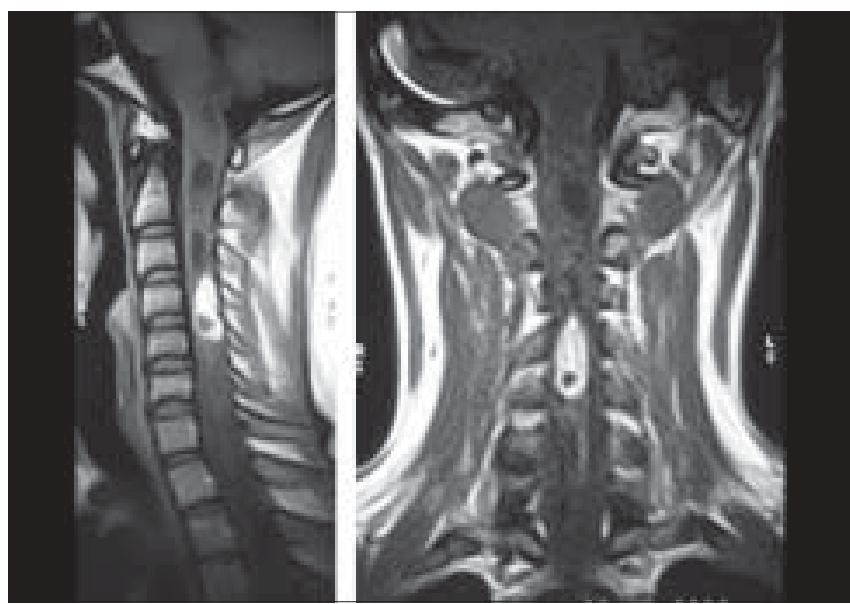

Figure 4: MRI sagittal and coronal T1-weighted image of the cervical cord showing heterogeneous enhancement of the intramedullary mass

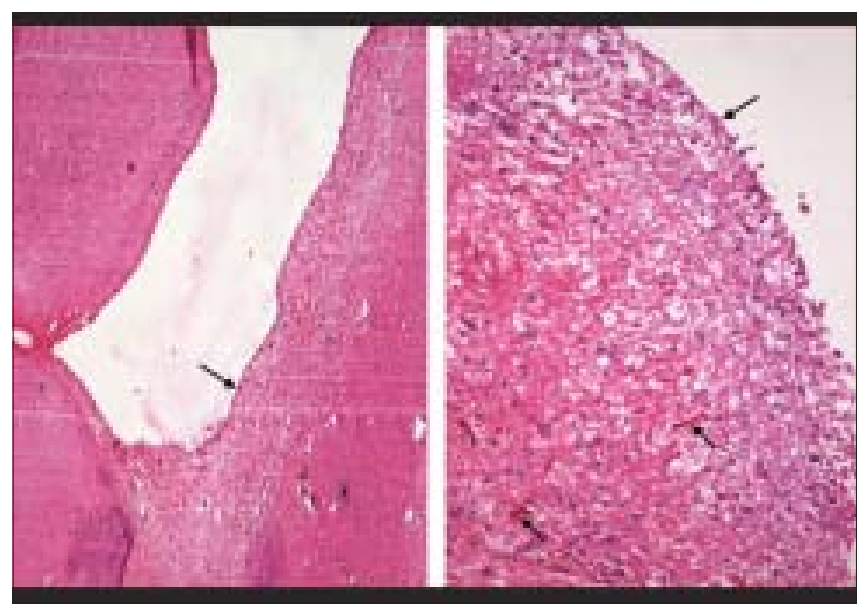

Figure 6: Low-magnification view shows a cystic lesion lined partially by ependyma (long arrow, A). The subependymal zone is loose, gliotic with numerous Rosenthal fibers (small arrows, B) A:H\&E ×40, B:H\&E ×200

syringomyelia: New observations. AJR Am J Roentgenol 1987;148: 381-91.

2. Parizel PM, Balériaux D, Rodesch G, Segebarth C, Lalmand B, Christophe C, et al. Gd-DTPA-enhanced MR imaging of spinal tumors. A.JR Am J Roentgenol 1989;152:1087-96.

3. Escourolle A, Poiner J, editors. Manual of basic neuropathology. Philadelphia: Saunders; 1973. p. 19-34

4. Williams B, Timperley WA. Three cases of communicating synngomyelia secondary to midbrain gliomas. J Neurol Neurosurg Psychiat 1976;40:80-8.

5. Greenfield JG. Synngomyelia and synngobulbia. In: Blackwood W, McMenemey WH, Mayer A, Norman RM, Russell DS, editors. Greenfield's neuropathology. Baltimore: Williams and Wilkins; 1963. p. 331-7.

Accepted on 26-01-2009

Source of Support: Nil, Conflict of Interest: None declared. 